\title{
Carbon dioxide balance and cost analysis for different scenarios of solid waste management
}

\author{
D. Panepinto \& G. Genon \\ DITAG Department, Politecnico di Torino, Italy
}

\begin{abstract}
The final destination of municipal solid wastes requires the realization and localization on the territory of important industrial plants (separation plants, WtE systems, final landfills, and also other innovative solutions, like digesters or gasifiers), together with the important aspects of cost; careful consideration is also required about the effects of externality, chiefly concerning carbon balance, with reference to GHG production. Taking into account the necessity to define the choice for the rational individuation of the most correct waste management system, in the present work we evaluated a specific Italian case relative to the waste management for a city located in Piedmont (North Italy): it is important to consider that the amount of wastes that are produced in this city corresponds to about $540.000 \mathrm{t} / \mathrm{y}$. For the correct management of this load we considered different scenarios, by introducing thermal structures (direct incineration and gasification plants) and other complementary systems (mechanical separation plants, anaerobic digesters). The alternative scenarios have been carefully studied and compared from the environmental and economic point of view in order to obtain suitable choice criteria. The results of the specific case analysis clearly indicate the environmental and economic convenience of the solution based on the direct incineration.
\end{abstract}

Keywords: incineration, gasification, anaerobic digestion, carbon dioxide balance, cost analysis, social costs.

\section{Introduction}

The final destination of municipal solid wastes requires the realization of important industrial plants (separation plants, thermal systems, final landfills, and eventually, biological reactors); for a correct choice, the aspect of costs must 
be carefully considered, but also the effects of externality must be taken into account, and in particular carbon balance must be evaluated in order to define the specific contribution to GHG production.

As regards the environmental impact it is possible to observe that the BAT adoption has led to a substantial reduction of many pollutants emission, but against this the impact arising from carbon dioxide release must be considered, and with this purpose the best energetic exploitation of the system must be obtained.

In the general structure of integrated waste treatment and disposal a strong improvement of selective collection, aimed at reuse and production of secondary materials, can today be observed. Downstream from this opportunity, there is however a very important flow of undifferentiated waste, to which also the residuals from the material valorization must be added; for this flux it is required to individuate suitable prospects for disposal. From this flow, that in any case represents a high percentage of the total waste production, the fraction useful for reuse (metal, glass, the organic compounds) is effectively removed and the remaining part is basically formed from a combustible fraction, a minor wet organic fraction and a residual substantially inert mineral fraction. On the basis of this composition, and by considering the interest for the thermoelectric cogenerative production from non-fossil sources, it is convenient to propose a perspective of energy recovery of this fraction, with a double aim: to find a correct destination for the disposal of this stream, and at the same time to contribute to production of energy in a compatible way.

A first choice that is today largely discussed concerns the energetic valorization of the undifferentiated flow (through direct combustion in incinerators or through treatment in plants using innovative technology, chiefly gasification plants), or, instead, the proposal of mechanical separation systems, downstream the selective collection, systems that appear essentially aimed at separation of three fractions, a fuel fraction (known as RDF, which can be designed for specific plants or introduced into the market of the fuels), a wet fraction (for which, with the possibility of biological stabilization in anaerobic digestion plants, also prospects of indirect energy valorization could be individuated), and finally a mineral fraction, for which a final landfill destination seems to be the only practical option possibility.

Between the two alternative above mentioned schemes, the first is certainly the most diffuse today, both in Italy and in the most technologically equipped part of the Europe, for simplicity reason, economic convenience, liberation from the problems of secondary flows except the necessity to dispose of the obtained ashes. As concerns the second scheme, the attention is today directed to it with always more important development hypothesis, on account of the fact that this scheme is considered more environmentally compatible, less impacting on the area in terms of necessary infrastructures, and more oriented in the direction of development of synergies with other plants that are already present on the territory.

In the present work we have carefully evaluated these different technologies for waste disposal and at the same time for the valorization of the wastes; in fact 
on the basis of the necessity to define a strategy of rational choice for the correct management of the wastes, the aim of the work is to individuate in a general way an evaluation methodology useful to define the correct solution for the management of the wastes produced in the examined area.

\section{Methodology}

As indicated in the introduction, the aim of this study is the comparison and the consequent best choice among scenarios for residual waste management, downstream from selective collection of the fractions that can be reused.

The first scenario that in this perspective is considered is that of combustion of the residues in conventional moving-grate system; this technology is today widely spread at national level and even at world level.

In opposition to this solution, great interest has been attributed to the perspective of waste gasification, chiefly in the scheme that is followed by energy use, but also potentially with the consideration about production of chemicals. In this sense it is surely convenient to mention the perspective of mechanical separation of undifferentiated waste into three main flows: a dry flow destined to a energetic valorization, a wet flow of organics destined for an anaerobic digestion with production of biogas and finally a stream with a predominant mineral composition, substantially inert, to be disposed of in a landfill. For a correct individuation of the more appropriated waste management system the two above reported technologies must be evaluated.

A correct approach to these aims must include the following steps:

- definition of an overall flow chart, which identifies the need for different equipment or plant systems that are needed for each scenario; this quantitative scheme must consider the appropriate mass balances for the individual components of the input wastes, and their intermediate and final destination;

- $\quad$ identification, by literature data, from notice of other plants or eventually from pilot tests, of the expected performance for the various equipment, in particular as regards the emission flows and the capacity for power generation (thermal and electric energy);

- evaluation of the effects of energy immission in the area where the supposed plant will be realized, and connected possibility to replace existing energetic generation capacities and corresponding pollutants flows;

- determination of the building costs for the all equipment that is introduced in each scenario, of the operative costs corresponding to the various items of consumption, of the economic returns from the sale of energy or of any materials;

- evaluation of the external costs, as they can be defined on the basis of emission flows and their cost of externality; these costs can be found, for example, in the ExternE project, or they can be determined on the basis of 
quality scenarios for the receiving environments and consequent evaluation of the effects of this quality on the external costs;

o From the point of view of the definition of external costs from the emissions of the disposal equipment, all the emissions to air, surface and underground water, soil should be conceptually considered; there is, in this context, a precise and well-proven method of approach that presents a particular reference to systems for waste disposal. In this paper, with the aim to arrive to a first comparison (orders of magnitude), but especially taking into account the results that are reported in previous literature studies, where the relative importance of different forms of impact is defined, it was considered sufficient to take into account in the evaluation of the externality costs the only external cost of $\mathrm{CO}_{2}$ emission, that can be correctly estimated by its contribution to the GHG and to the consequent climate change;

- As a further consideration about the discussion on the acceptability of this important simplification, another aspect should be taken into account, in addition to the fact that this form of impact is the more significant, and so the used approximation is certainly minimized; the carbon dioxide impact can be exactly calculated on the basis of mass and energy balance, as opposed to other forms of impact, for which different specific technological structures could lead to large variations in the emission levels. In this sense the results that will be obtained at the end of the elaboration can be considered as significant and acceptable.

- Definition of the final social cost (industrial plus external) are obtained for the disposal by also taking into account the contemporary strategy of energy production.

The development of a calculation procedure so defined seems to propose a general scheme, but the specific results are obviously a consequence of different local problems (pre-existing scenarios for power generation, environmental sensitivity of the interested area, quantitative dimension of the problem to be solved, ability to handle significant technological innovations); hence it must be stressed the fact that it is impossible to establish an optimal technology choice in a general sense, but this outcome should result only from a specific analysis for a particular case. It seems impossible to explore all the different possibilities that are present in the areas where this study could be addressed, so it was decided in this paper to illustrate only a specific particular case by considering with this simplification to clarify the modalities of implementation of the presented methodology; from this reconstruction of scenario some more general considerations should be extracted.

\section{Objective of the study}

The different above illustrated technology schemes have been carefully evaluated in a specific Italian case study: it consists in the correct individuation 
of waste management modality for final destination of wastes that are produced in the city of Piedmont, in the north of Italy. The amount of the wastes produced in this city corresponds to about $540.000 \mathrm{t} / \mathrm{y}$ (constituted by $470.000 \mathrm{t} / \mathrm{y}$ of MSW and $70.000 \mathrm{t} / \mathrm{y}$ of sovvalli). In this city the realization of an incineration plant with a capacity of about $420.000 \mathrm{t} / \mathrm{a}$ was already decided upon, but as a consequence of a higher estimated production a new waste management overall solution is required (of course the incineration plant already under construction will be part of any strategy).

For the correct individuation of the waste management we studied three different scenarios:

- $\quad$ scenario A: it corresponds to the thermal treatment with direct combustion in a large incineration plant of the whole amount of the wastes produced in the city;

- $\quad$ scenario B: it is similar to scenario 1, but with the adoption, together to an incineration plant, also of a gasification plant, by sharing the total waste production between the two thermal plants;

- scenario C: firstly the separation of the whole amount of the wastes produced in the city is considered, and from this operation the direct combustion in an incineration plant of the obtained dry fraction and the management in a dry anaerobic digestion plant of the wet fraction are introduced.

On account of the observed impossibility of potentiality considerations to send the RDF that could be obtained to a cement plant, or to other existing plants, this opportunity has not been considered.

The three introduced scenarios have been evaluated by means of the following tools:

- $\quad$ analysis of the operating systems that must be present in the three different scenarios, and corresponding definition of the required plants and the landfill necessity;

- carbon dioxide balance; it has been performed by using mass and energy balance, with individuation of two emission factors (expressed as $\mathrm{tCO}_{2} / \mathrm{t}$ waste and $\mathrm{tCO}_{2} / \mathrm{MWh}$ );

- cost analysis;

- definition of the social (industrial plus external) costs for the analyzed scenarios, with application of the above-mentioned tools.

\subsection{Fluxes characterization}

As concerns the product composition of waste in input to the various systems that are present in the different scenarios, there are some differences. In scenarios A and B we assumed to treat a MSW with the product composition that is reported in table 1 . In the scenario $C$, as we mentioned, the MSW (composition as table 1) is initially sent to a process of mechanical separation. From this treatment two flows (dry and wet respectively), are obtained, with a product composition that has been obtained by numerical calculations on the 
basis of procedure of literature (J.R. Burton et al. [1]); the results are shown in table 2 .

In table 3 the operative parameters are reported that were used in the different elaborations. For all scenarios we considered a cogenerative disposition.

Table 1: $\quad$ MSW product composition.

\begin{tabular}{|c|c|}
\hline PRODUCT COMPOSITION (scenarios A e B) \\
\hline Product fraction & $\%$ \\
\hline Paper & 25 \\
\hline Paperboard & 7 \\
\hline Textile & 5 \\
\hline Wood & 1 \\
\hline Plastic & 19 \\
\hline Glass and inert & 9 \\
\hline Metal & 3 \\
\hline Domestic organic & 22 \\
\hline Green materials & 2 \\
\hline Fine materials & 5 \\
\hline
\end{tabular}

Table 2: $\quad$ Treated waste product composition.

\begin{tabular}{|c|c|c|}
\hline \multicolumn{3}{|c|}{ PRODUCT COMPOSITION (scenario C) } \\
\hline Product fraction & $\begin{array}{c}\text { Wet fraction (in input } \\
\text { at digester) }\end{array}$ & $\begin{array}{c}\text { Dry fraction (in input } \\
\text { at incineration plant) }\end{array}$ \\
\hline Paper & $11 \%$ & $32 \%$ \\
\hline Paperboard & - & $9 \%$ \\
\hline Textile & - & $7 \%$ \\
\hline Wood & - & $1 \%$ \\
\hline Plastic & - & $25 \%$ \\
\hline Glass and inert & - & $13 \%$ \\
\hline Metal & $81 \%$ & $4 \%$ \\
\hline Domestic organic & - & $2 \%$ \\
\hline Fine materials & & $7 \%$ \\
\hline
\end{tabular}

\section{Elaborations and results}

\subsection{Analysis of the systems}

In the following table we can see the operating plants that are present in the three different scenarios and the potentiality of them. We can also see the landfill necessity for each of the considered scenarios (the value has been obtained with elaboration of the data reported in table 3). 
Table 3: $\quad$ Parameters used in the elaborations.

\begin{tabular}{|c|c|}
\hline Parameters & Value \\
\hline MSW LHV [MJ $/ \mathrm{kg}]$, scenarios A and B & 11,5 \\
\hline $\begin{array}{c}\text { Dry waste fraction (treated waste) LHV [MJ/kg], } \\
\text { scenario C }\end{array}$ & 13,7 \\
\hline Plant availability [h/a], scenarios A, B and C & 7.800 \\
\hline $\begin{array}{l}\left.\text { Combustion energetic yield ( } \eta_{\text {plant inc }}\right) \text {, scenarios } A \text {, } \\
\text { B and C }\end{array}$ & $90 \%$ (ATO-R [2]) \\
\hline Gasification energetic yield ( $\left.\mathrm{n}_{\text {plant gas }}\right)$, scenario B & $80 \%$ (ATO-R [2]) \\
\hline $\begin{array}{l}\text { Electric energy generation efficiency, scenarios A } \\
\text { and B }\left(\eta_{\text {el t }}\right)[\%] \text {, scenarios A, B and C }\end{array}$ & 19\% (TRM [3]) \\
\hline $\begin{array}{c}\text { Thermal energy generation efficiency, scenarios A } \\
\left.\text { and B ( } \eta_{\text {th }}\right)[\%] \text { scenarios A, B and C }\end{array}$ & $51 \%($ TRM [3]) \\
\hline $\begin{array}{c}\text { Electric energy generation efficiency }\left(\eta_{\text {el b }}\right) \\
{\left[\mathrm{KWh} / \mathrm{Nm}^{3} \text { biogas }\right] \text {, scenario C }}\end{array}$ & 2,5 (A. Canovai [4]) \\
\hline $\begin{array}{l}\text { Thermal energy gen. efficiency }\left(\mathrm{\eta}_{\text {th }} \mathrm{b}\right) \\
{\left[\mathrm{KWh} / \mathrm{Nm}^{3} \text { biogas }\right] \text {, scenario } \mathrm{C}}\end{array}$ & 1,9 (A. Canovai [4]) \\
\hline $\begin{array}{l}\text { Avoided } \mathrm{CO}_{2} \text {, electric recover }-\mathrm{EF} \text { el }[\mathrm{g} \\
\left.\mathrm{CO}_{2} / \mathrm{kWh}\right] \text {, scenarios } \mathrm{A}, \mathrm{B} \text { and } \mathrm{C}\end{array}$ & 675 (GME [5]) \\
\hline $\begin{array}{l}\text { Avoided } \mathrm{CO}_{2} \text {, thermal recover }-\mathrm{EF}_{\text {th }} \\
{\left[\mathrm{gCO}_{2} / \mathrm{kWh}\right] \text {, scenarios } \mathrm{A}, \mathrm{B} \text { and } \mathrm{C}}\end{array}$ & $\begin{array}{c}210(\mathrm{GME}[5] \\
\text { modification by } \\
\text { Burton [1]) }\end{array}$ \\
\hline $\begin{array}{c}\text { Biogas production }\left(\eta_{\text {biogas }}\right) \text { [\% on organic in input } \\
\text { at the digester], scenario C }\end{array}$ & $\begin{array}{l}20 \text { (De Baere and } \\
\text { Boelens }[6])\end{array}$ \\
\hline $\begin{array}{l}\text { Digestate production [\% on organic in input at the } \\
\text { digester], scenario C }\end{array}$ & $\begin{array}{l}80 \text { (De Baere and } \\
\text { Boelens [6]) }\end{array}$ \\
\hline $\begin{array}{l}\text { Bottom ash production [\% on waste in input at } \\
\text { thermal plant], scenarios A, B and C }\end{array}$ & 22 \\
\hline $\begin{array}{l}\text { Fly ash production [\%on waste in input at thermal } \\
\text { plant], scenarios } \mathrm{A}, \mathrm{B} \text { and } \mathrm{C}\end{array}$ & 4 \\
\hline
\end{tabular}

\subsection{Carbon dioxide balance}

As we have seen, in account of the fact that the carbon dioxide is one of the main GHG, a carbon dioxide balance study is required for the impact evaluation on climate change of the different proposed scenarios.

In order to obtain a carbon dioxide balance we propose the following considerations:

- for the scenario A and B, where only thermal treatment of the waste is introduced, we considered that all the carbon that is contained in the entering waste $\left(\mathrm{C}_{\text {total }}\right)$ leads to carbon dioxide; so the following equation can be used:

$$
\mathrm{CO}_{2 \text { produced }}[\mathrm{t}]=\mathrm{C}_{\text {total }} * \mathrm{PM} \mathrm{CO}_{2} / \mathrm{PM} \mathrm{C} * \text { Total waste }
$$


- for scenario $\mathrm{C}$, we considered the carbon dioxide coming from separation, the carbon dioxide coming from incineration and obviously, also in this case, the carbon contained in the input waste and transformed in carbon dioxide; we considered also the carbon remaining in the digestate. So for this scenario it is valid the following equation:

with:

$$
\begin{aligned}
& \mathrm{CO}_{2} \text { produced }[\mathrm{t}]=\mathrm{CO}_{2} \text { separation } \\
&+\mathrm{CO}_{2} \text { incineration } \\
&+\mathrm{CO}_{2 \text { biogas }}+\left(\mathrm{C}_{\text {digestate }}-\mathrm{C}_{\text {soil remain }}\right) * 44 / 12
\end{aligned}
$$

$\mathrm{CO}_{2}$ separation $=67.5 \mathrm{~kg} \mathrm{CO}_{2} / \mathrm{t}_{\text {waste }}$ (Blengini and Genon [7] modified with elaboration of table 3]

$\mathrm{C}_{\text {soil remain }}=10 \% \mathrm{C}_{\text {digestate }}$ (Boldrin et al. [8]; Moller et al. [9])

- for the three scenarios we took into account the carbon dioxide coming from substituted energetic plants.

$$
\mathrm{CO}_{2 \text { avoided }}=\text { Power }_{\text {th, el }} * \text { availability }(\mathrm{h} / \mathrm{y}) * \mathrm{EF}_{\text {th,el }}
$$

- for the energy production we utilize the following equation:

$$
\begin{gathered}
\text { Energy thermal plant }[\mathrm{MWh}]=\mathrm{LHV} * \text { tot }_{\text {waste }} * \eta_{\text {plant inc, gas }} * \eta_{\mathrm{el}, \text { th , I }} \\
\text { Energy anaerobic digestion }[\mathrm{MWh}]=\text { tot }_{\text {waste }} * \eta_{\text {biogas }} * \eta_{\text {th, el, b }}
\end{gathered}
$$

\begin{tabular}{|c|c|c|c|}
\hline & Scenario A & Scenario B & Scenario C \\
\hline Waste treated $[\mathrm{t} / \mathrm{y}]$ & 540.000 & 540.000 & 540.000 \\
\hline Incineration plant $[\mathrm{t} / \mathrm{y}]$ & $540.000 *$ & $420.000^{* *}$ & $408.400 * * *$ \\
\hline Gasification plant $[\mathrm{t} / \mathrm{y}]$ & - & 120.000 & - \\
\hline Separation plant $[\mathrm{t} / \mathrm{y}]$ & - & - & 540.000 \\
\hline Anaerobic digestion plant $[\mathrm{t} / \mathrm{y}]$ & - & - & 131.600 \\
\hline Landfill (bottom ash) [t/y] & 118.800 & 118.800 & 89.848 \\
\hline Landfill (fly ash) [t/y] & 21.600 & 21.600 & 16.336 \\
\hline Landfill (digestate) $[\mathrm{t} / \mathrm{y}]$ & - & - & 105.280 \\
\hline Total landfill $[\mathrm{t} / \mathrm{y}]$ & 140.400 & 140.400 & 202.776 \\
\hline \multicolumn{4}{|c|}{$\begin{array}{l}* 540.000 \mathrm{t} / \mathrm{y}=470.000 \mathrm{t} / \mathrm{y}(\mathrm{MSW})+70.000 \mathrm{t} / \mathrm{y}(\text { sovvalli) } \\
* * 420.000 \mathrm{t} / \mathrm{y}=350.000 \mathrm{t} / \mathrm{y}(\mathrm{MSW})+70.000 \mathrm{t} / \mathrm{y}(\text { sovvalli) } \\
* * * 408.400 \mathrm{t} / \mathrm{y}=338.400 \mathrm{t} / \mathrm{y}(\text { dry fraction from separation })+70.000 \mathrm{t} / \mathrm{y} \\
\text { (sovvalli) }\end{array}$} \\
\hline
\end{tabular}

Table 4: $\quad$ Analysis of the systems.

So, on the basis of the above reported considerations and on the basis of the data that are reported in tables 1, 2 and 3, in table 5 we can see the results of the carbon dioxide balance.

By analyzing the results of table 5 we can see the environmental advantage for the scenario A that introduces the thermal treatment of the total amount of the produced waste with direct combustion in incineration plant. 
Table 5: $\quad$ Results of the carbon dioxide balance.

\begin{tabular}{|c|c|c|c|}
\hline & Scenario A & Scenario B & Scenario C \\
\hline Treated wastes [t/y] & 540.000 & 540.000 & 540.000 \\
\hline $\begin{array}{c}\text { Produced energy } \\
{[\mathrm{MWh}]}\end{array}$ & 1.087 .619 & 1.062 .779 & 1.092 .159 \\
\hline Produced $\mathrm{CO}_{2}[\mathrm{t} / \mathrm{y}]$ & 841.812 & 841.812 & 866.408 \\
\hline $\mathrm{t} \mathrm{CO}_{2}$ / t wastes & 1.56 & 1.56 & 1.60 \\
\hline $\mathrm{t} \mathrm{CO}_{2} / \mathrm{MWh}$ & 0.77 & 0.79 & 0.79 \\
\hline Avoided $\mathrm{CO}_{2}[\mathrm{t} / \mathrm{y}]$ & 365.673 & 357.321 & 375.504 \\
\hline t $\mathrm{CO}_{2} / \mathrm{t}$ wastes* & 0.88 & 0.90 & 0.91 \\
\hline t $\mathrm{CO}_{2} / \mathrm{MWh}^{*}$ & 0.44 & 0.46 & 0.45 \\
\hline \multicolumn{4}{|c|}{$*$ at net of the avoided $\mathrm{CO}_{2}$} \\
\hline
\end{tabular}

In this context it is important to highlight that, also by considering only the fossil fraction of carbon dioxide, the same result is obtained; in fact it must be considered that the definition of the share of fossil and biogenic carbon dioxide depends only on the waste composition in input to the various scenarios, and not on the management systems that are adopted.

\subsection{Cost analysis}

After these results it is important to consider also the results of the cost analysis (table 6).

Table 6: $\quad$ Cost analysis.

\begin{tabular}{|c|c|c|c|}
\cline { 2 - 4 } \multicolumn{1}{c|}{} & Scenario A & Scenario B & Scenario C \\
\hline Capital cost $[€]$ & 250.000 .000 & 300.000 .000 & 305.000 .000 \\
\hline Amortization cost $[€ / \mathrm{t}]$ & 46.3 & 55.6 & 56.5 \\
\hline Operative cost $[€ / \mathrm{t}]$ & 76 & 90 & 112 \\
\hline Energy revenue $[€ / \mathrm{t}]$ & 102 & 97 & 97 \\
\hline External cost, $\mathrm{CO}_{2}[€ / \mathrm{t}]$ & 16.7 & 17 & 17.2 \\
\hline
\end{tabular}

The capital cost and the operative cost are defined on the basis of the market costs relative to the different plants that are present in each scenario, by taking also into account a scale effect.

The amortization cost is calculated with the following equation:

Amortization cost $[€ / t]=($ Capital cost $* 10 \%) /$ waste total with:

$10 \%=$ amortization percentage [sources: capital Italian market].

The energy revenue is calculated on the basis of the market price relative to the electric and thermal energy produced and of also of the prizes for energy 
obtained from renewable sources (in Italy green certificates). The external cost is defined on the basis of the $\mathrm{CO}_{2}$ external cost (Rapporto ExternE [10]).

Also, in this case, scenario A leads to the best costs.

\subsection{Definition of the social cost}

After we individuated and examined the environmental and economic aspects of the scenarios. We have performed a global comparison of them by using the tool of the social cost.

The social cost is the result of the addition (in our study with ratio 1:1) of the environmental aspects that have been defined by means of the calculated balances (table 5) and transformed in an external cost, and of the economic aspects, as they have been defined from a specific analysis (table 6). We obtain, in this way, a final overall index of global evaluation of the analyzed aspects; by this index it is possible to arrive to an organic and global comparison of the different proposed scenarios.

On the basis of the above reported discussion the social cost is defined by the following equation:

$$
\text { Social cost }[€ / t]=\text { industrial cost }+ \text { external cost }
$$

The industrial cost is composed by the following parameters: "amortization cost", "operative cost" and "energy revenue".

By analyzing the results that are reported in the table it shows that the best scenario is the scenario A, where the thermal treatment in an incineration plant of the total amount of waste produced in the studied city is used.

\section{Conclusions}

On the basis of the reported elaborations it is possible to arrive at the following specific considerations, with a value that is referred to the considered local situation:

Quantitative considerations. From a quantitative point of view, a fundamental problem that is observed is the residual necessity of landfill. By analyzing the results of table 4 we can observe that the bottom ash landfill necessity, in the scenario $\mathrm{C}$, is lower in comparison with the values for the only thermal systems, but, in the same scenario $\mathrm{C}$, the necessity of a big volume for the management of digestate arises. In fact the only real destination for the digestate, in the analyzed context, on the base of the national legislation, is its landfill disposal. Plus, the possibility to send it to thermal treatment must in fact be excluded: in consideration of the very large flow rate it would require the construction of a new facility, and also it is very unlikely a place in an existing conventional grate system for biomass thermal utilisation could be found. In addition to these reasons, the thermal destination must be excluded also on account of thermotechnical considerations: the digestate flow present has a significant water content and consequently it would significantly worsen the conditions of 
combustion. It is also impossible to suggest its use for agricultural purposes as fertilizer or a soil improver, on account of existing strict quality requirements imposed by Italian law (Legislative Decree 217/2006).

Environmental considerations. From the point of view of the environmental impact we distinguish between local and global impact. From the local point of view the main criticality is represented by the incineration emissions: for their limitation it is necessary to realize a structure that has been conceived on the basis of the BAT; in this case its suitability, and consequently avoidance of local environmental impact, can be considered as acquired. On this basis the use of incineration for MSW or for the treatment only of a separated dry fraction is not considered to lead to appreciable differences. In the scenario of the MBT plant there are two additional elements must be taken into account as the origin of impact: the separation plant and the digester; from these plants, chiefly, the impact from the separator must be evaluated on account of odour emissions, while for the digester we can establish that with a convenient and efficient plant structure the impact can be eliminated. From the point of view of the bottom ashes there are no differences among the various scenarios, while from the point of view of the management of the digestate its landfill disposal, without further stabilization operations, could lead to local impacts due to volatilization phenomena. Finally, from the point of view of global impact, this must be considered chiefly with reference to carbon dioxide emissions. From the previously discussed calculations (table 5), it can be observed an advantage for the direct total thermal treatment.

Economic considerations. From the point of view of the costs, we observe (table 6) that the investment cost is lower for the scenario A that uses the direct combustion in an incineration plant. The scenario $\mathrm{C}$ has an investment cost that can be compared with that of the scenario B. Also from the point of view of the operative cost the scenario A results are the more convenient. For the scenario $\mathrm{C}$ the adoption before the incineration plant of a another step of pre-treatment necessarily entails an important increase in the operative costs, in comparison with the two thermal scenarios. Finally, from the point of view of the energetic revenue, this very important and meaningful aspect is higher in the scenario A. The external costs of the $\mathrm{CO}_{2}$ for the three scenarios obviously reflect the trends of the $\mathrm{CO}_{2}$ emissions at net of the avoided $\mathrm{CO}_{2}$ avoided.

For the above discussed thematic considerations a large confirmation can be obtained by analyzing the elaborations results of the social cost: in fact it is able to put together the environment and the economic aspects (table 7). By analyzing this index, with the purpose of a general overview of the analyzed scenarios, it is clear that the scenario is more favorable for option A.

On the basis of the above reported discussion, from the general point of view, the scientific relevance of the conducted work consists of the definition of a logical scheme for comparison that can be adapted to different management and disposal requirements.

In fact, as has been shown, the created comparison methodological scheme, valid and tested for the specific analyzed case, can be considered a useful 
Table 7: $\quad$ Social cost.

\begin{tabular}{|c|c|c|c|}
\cline { 2 - 4 } \multicolumn{1}{c|}{} & Scenario A & Scenario B & Scenario C \\
\hline Amortization cost $[€ / \mathrm{t}]$ & 46.3 & 55.6 & 56.5 \\
\hline Operative cost $[€ / \mathrm{t}]$ & 76 & 90 & 112 \\
\hline Energy revenue $[€ / \mathrm{t}]$ & 102 & 97 & 97 \\
\hline Industrial cost $[€ / \mathbf{t}]$ & $\mathbf{2 0 . 3}$ & $\mathbf{4 8 . 6}$ & $\mathbf{7 1 . 5}$ \\
\hline External cost, $\mathrm{CO}_{2}[€ / \mathrm{t}]$ & 16.7 & 17 & 17.2 \\
\hline Social cost $[€ / \mathbf{t}]$ & $\mathbf{3 7}$ & $\mathbf{6 8 . 6}$ & $\mathbf{8 8 . 7}$ \\
\hline
\end{tabular}

approach for the definition of the best solution for specific territorial necessity of waste management.

\section{References}

[1] J. R Burton et al., "Waste sorting and RDF - Production in Europe", Elsevier Applied Science Publishers, 1985;

[2] ATO-R - Verifica della fattibilità di un impianto di trattamento termico dei rifiuti a tecnologia innovativa nella provincia di Torino, Ingegneria Ambientale, Quaderni, 51 (2010);

[3] TRM - Impianto di termovalorizzazione dei rifiuti della provincia di Torino - Italia. "Bilanci termici e di massa", 2006;

[4] A. Canovai, Consorzio Italiano Compostatori, "La proposta operativa: modello tecnico-economico impiego sistema UMICA", workshop, Salerno 18 March 2009;

[5] GME - Gestore Mercati Energetici. Website: $<$ http://www.mercatoelettrico.org/It/Default.aspx> accessed 12 July 2010;

[6] L. De Baere and J. Boelens (OWS) "Rest or mixed waste sorting digestion - separation for the recovery of recyclables and energy", website: $<$ http://www.ows.be>, accessed 12 July 2010;

[7] Blengini GA., Genon G. (Politecnico di Torino),"LCA del sistema integrato dei RSU nella Provincia di Torino", Provincia di Torino, July 2008;

[8] Boldrin A. et al., "Composting and compost utilization accounting of greenhouse gases and global warming contributions", Waste Management and Research, 2009:27, 800-812;

[9] Moller J., et al., "Anaerobic digestion and digestate use: accounting of greenhouse gases and global warming contribution", Waste Management and Research, 2009:27, 813-824;

[10] Valore di mercato (Rapporto Externeè), website: $<$ http://www.externe.info>; accessed 12 July 2010. 